\title{
Efficacy of pediatric colonoscopy used as push enteroscopy in the management of capsule endoscopy findings
}

\author{
F. Pérez Roldán, P. González Carro, M. L. Legaz Huidobro, O. Roncero García-Escribano, \\ M. Ynfante Ferrús, S. Aoufi, N. Sánchez-Manjavacas Muñoz and F. Ruiz Carrillo \\ Service of Digestive Diseases. Hospital General La Mancha-Centro. Alcázar de San Juan, Ciudad Real. Spain
}

\begin{abstract}
Background: recent advances in endoscopy have enabled us to explore the small intestine more efficiently, both with capsule endoscopy and double-balloon enteroscopy. However, these methods are not available in all hospitals. Therefore, when capsule endoscopy reveals proximal jejunal lesions, a possible alternative for treatment could involve push enteroscopy combined with colonoscopy. Lesions can thus be marked for subsequent monitoring.

Objectives: to describe the efficacy of pediatric colonoscopy for diagnosis, the marking of the area explored, and therapeutic options.

Material and methods: between October 2007 and September 2008 a total of 21 enteroscopies were performed using a pediatric colonoscope. Nine of these were used to take jejunal biopsy samples due to suspected disease of the mucosa. In 10 of the remaining 12, capsule endoscopy revealed lesions (vascular malformations or jejunal bleeding), and in 2 intestinal transit time was analyzed due to suspected jejunal stenosis. We used a PENTAX EC-3470-LK pediatric colonoscope, whose 11.6-mm sectional diameter and 3.8-mm working channel make it possible to administer all the usual endoscopic treatments.

Results: therapeutic endoscopy was performed on 7 men and 5 women (mean age 63.3 years). Jejunal lesions were observed in 10 cases ( 5 cases of angiodysplasia, 2 cases of jejunal stenosis, 1 case of nonmalignant thickened jejunal folds, 1 eroded submucosal tumor, and 1 case of duodenal and jejunal varices). The most distal area was marked with India ink (2), hemoclips (4), or both to help locate the lesions using simple abdominal radiography or capsule endoscopy.

Conclusions: jejunal enteroscopy enabled a firm diagnosis to be made in most of the patients studied. We were able to treat $58 \%$ of patients and mark the areas explored for subsequent follow-up. With hemoclips we were able to locate the most distal point explored using simple abdominal radiography.
\end{abstract}

Key words: Enteroscopy. Pediatric colonoscopy. Capsule endoscopy. Treatment. Lesion markers.

Received: 10-02-09.

Accepted: 17-04-09.

Correspondence: Francisco Pérez Roldán. Sección de Apto. Digestivo. Hospital General La Mancha-Centro. Avda. de la Constitución, 3. 13600 Alcázar de San Juan. Ciudad Real, Spain. e-mail: fperezroldan@gmail.com
Pérez Roldán F, González Carro P, Legaz Huidobro ML, Roncero García-Escribano O, Ynfante Ferrús M, Aoufi S, SánchezManjavacas Muñoz N, Ruiz Carrillo F. Efficacy of pediatric colonoscopy used as push enteroscopy in the management of capsule endoscopy findings. Rev Esp Enferm Dig 2009; 101: 468-476.

\section{INTRODUCTION}

In recent years, there have been several advances in the endoscopic techniques used for both the diagnosis and treatment of diseases of the gastrointestinal tract. However, the small intestine has not benefited from these advances as much as it might due to difficulties in endoscopic access. Since the arrival of push endoscopy in 1971, it was only possible to explore the proximal jejunum to a distance of about $50 \mathrm{~cm}$ beyond the ligament of Treitz (1). The subsequent arrival of the video-endoscope and insertion tube made it possible to view the whole jejunum.

The latest discoveries have enabled us to better explore the small intestine using 2 methods: capsule endoscopy and double-balloon enteroscopy (2-9). As a diagnostic method, capsule endoscopy has presented us with a new challenge, namely the choosing of the therapeutic or confirmatory approach to lesions found $(6,7,9)$.

Hospitals with a small-intestine unit equipped with a double-balloon enteroscope and push enteroscope have been able to provide an effective solution in a large number of cases. However, hospitals in which these facilities are not available must turn to non-balloon enteroscopy to treat jejunal lesions. Colonoscopy is a well-recognized alternative, although its rigidity and caliber prevent it from advancing smoothly in the jejunum. An interim solution can be found in the pediatric colonoscope, which is smaller in diameter and more flexible, and has a working channel that is suitable for administering therapy. 
In this study, we aim to verify the results of pediatric colonoscopy in the diagnosis and treatment of lesions found by capsule endoscopy (except where contraindicated).

\section{MATERIAL AND METHODS}

This is a prospective descriptive study carried out at our institution (Hospital General La Mancha-Centro, Alcázar de San Juan, Spain) between October 2007 and September 2008. We performed 21 push endoscopies using a pediatric colonoscope in patients with lesions found, in theory, by capsule endoscopy (except where contraindicated), and in those who had to receive endoscopic treatment or undergo biopsy sampling from this area.

We used a PENTAX EC-3470-LK pediatric colonoscope, which is $160 \mathrm{~cm}$ long, with an 11.6- $\mathrm{mm}$ sectional diameter and 3.8-mm working channel. This channel allows us to administer any type of endoscopic treatment with material in standard use in the endoscopy unit (sclerosis needles, hemoclips, biopsy marking clips, argon probes). Enteroscopy was performed without radiographic monitoring, as these facilities were not available for this procedure. An insertion tube was not used either, as the condition to be treated and the biopsy specimen were in the proximal jejunum. All the patients were under deep sedation with propofol, and intravenous hyoscine butylbromide was used as a spasmolytic. In some of the last patients to undergo enteroscopy, we marked the most distal area with India ink, hemoclips (an abdominal radiograph was taken to locate the area of the lesion), or both to help determine the topographic distribution of the lesions using a new capsule endoscopy and to help the surgeon in cases of active bleeding. We did not record the number of centimeters explored, as this value varies according to the length of the intestinal loop formed by the passage of the colonoscope.

Enteroscopy was used to obtain jejunal biopsy specimens in 9 patients as a result of suspected mucosal involvement after capsule endoscopy. In 10 of the remaining 12 patients, capsule endoscopy revealed lesions, and in 2, only intestinal transit time was analyzed due to a high suspicion of jejunal stenosis (1 patient had Crohn's disease and 1 had a jejunal tumor).

\section{RESULTS}

The study sample comprised 7 men $(58.3 \%)$ and 5 women. Mean age was $63.3 \pm 16.4$ years. The most common reason for consultation was iron-deficiency anemia (5), followed by bleeding in the lower digestive tract (4). Gastroscopy and colonoscopy findings were mostly unremarkable, the most interesting being hiatal hernia, esophageal varices, and gastric angiodysplasia.
Intestinal transit time was measured in 10 patients $(83.3 \%)$ and values were within the reference range in all but 2 patients, both of whom had jejunal stenosis. Capsule endoscopy revealed jejunal bleeding in 6 patients (blood was visible in the jejunum, although the lesion it came from was not) and angiodysplasia in 4 . Mean hemoglobin level was $10.5 \pm 2.86 \mathrm{~g} / \mathrm{dl}$ and ferritin level was $103.6 \pm 199.4 \mathrm{ng} / \mathrm{ml}$; however, if we analyze the subgroup of patients with anemia or digestive bleeding of unknown origin, we see that their hemoglobin level was lower than $10 \mathrm{~g} / \mathrm{dl}$, with a mean value of 8.3 $\mathrm{g} / \mathrm{dl}$. Patient characteristics, laboratory findings, and the results of gastroscopy, colonoscopy, and radiography are shown in detail in table I.

Of the 12 patients who underwent push enteroscopy for therapeutic reasons, endoscopic lesions were observed in the jejunum in 10 ( 5 cases of angiodysplasia, 2 cases of jejunal stenosis, 1 case of thickened jejunal folds and normal histology, 1 case of eroded submucosal tumor, and 1 case of duodenal and jejunal varices with hypertensive enteropathy). Table II shows the correlation between the findings of capsule endoscopy and those of endoscopy. It also shows the treatment administered and whether or not the lesion or last section explored was marked.

In patients 7 and 10, the lesions were marked more precisely with India ink to cover the need for another capsule endoscopy. In 4 patients (numbers 3, 4, 10, and 11 ), the lesion was marked with hemoclips, and in 2 cases the most distal end was also marked (Fig. 1). The patient with jejunal stenosis due to Crohn disease (Fig. 2) needed 3 sessions of dilation with a controlled radial expansion balloon (12-15 and 15-18 $\mathrm{mm}$ ) until the endoscope could be inserted. Given that the stenosis partially closed between sessions, intralesional corticosteroids (triamcinolone, at one 10-mg injection per quadrant) were administered during the last dilation session, thus enabling the patient to eat without difficulty.

Follow-up ranged from 6 to 18 months. Patients with angiodysplasia did not have to be readmitted due to bleeding of the lower digestive tract, and their anemia was better controlled.

It is noteworthy that there were no complications arising from enteroscopy or the treatment administered.

\section{DISCUSSION}

The small intestine can be explored using capsule endoscopy (2) and measurement of intestinal transit time (3). Both techniques serve diagnostic purposes only, and enteroscopy or surgery are necessary to treat any lesions found during exploration. The appropriate enteroscopic technique is double-balloon enteroscopy (7-12), which is only available in some of the hospitals of the National Health System. We enquire what can be done to treat jejunal lesions that are accessible by push enteroscopy or 
Table I. Patient characteristics, laboratory findings, and results of explorations

\begin{tabular}{|c|c|c|c|c|c|c|c|c|c|}
\hline Patient Number & Age & Sex & Symptom & $H b$ & MCV & Ferritin & Gastroscopy & Colonoscopy & Intestinal transit \\
\hline 1 & 42 & M & Abdominal pain & 16.5 & 89 & 22 & $\mathrm{~N}$ & $\begin{array}{l}\text { Stenosis, } \\
\text { anastomosis }\end{array}$ & 2 stenoses \\
\hline 2 & 78 & M & Anemia & 9.5 & 77.5 & 22 & Hiatal hernia & $\mathrm{N}$ & $\mathrm{N}$ \\
\hline 3 & 74 & $\mathrm{~F}$ & Anemia & 6 & 76.1 & 76 & $\mathrm{~N}$ & $\mathrm{~N}$ & $\mathrm{~N}$ \\
\hline 4 & 65 & $M$ & LDB & 11 & 81 & 42 & $\mathrm{~N}$ & $\mathrm{~N}$ & - \\
\hline 5 & 75 & $M$ & Anemia & 8.5 & 89 & 725 & $\begin{array}{c}\text { Esophageal diverticulum, } \\
\text { chronic gastritis }\end{array}$ & $\mathrm{N}$ & $\mathrm{N}$ \\
\hline 6 & 63 & $\mathrm{~F}$ & Anemia & 9.8 & 101.5 & 108 & $\begin{array}{c}\text { Esophageal varices, } \\
\text { gastric angiodysplasia (3) }\end{array}$ & $\mathrm{N}$ & $\mathrm{N}$ \\
\hline 7 & 75 & $\mathrm{~F}$ & LDB & 12.7 & 76.6 & 51 & Tiny gastric polyps & $\mathrm{N}$ & $\mathrm{N}$ \\
\hline 8 & 49 & $\mathrm{~F}$ & Iron deficiency & 13.7 & 84.1 & 9 & $\mathrm{~N}$ & $\mathrm{~N}$ & $\mathrm{~N}$ \\
\hline 9 & 65 & $M$ & DBUO & 7.7 & 88.8 & 13 & $\begin{array}{l}\text { Esophageal varices } \\
\text { without bleeding }\end{array}$ & $\mathrm{N}$ & $\mathrm{N}$ \\
\hline 10 & 75 & $\mathrm{~F}$ & LDB & 10.9 & 74.5 & 6 & Antral vascular ectasia & $\mathrm{N}$ & $\mathrm{N}$ \\
\hline 11 & 74 & M & LDB & 11.8 & 79.2 & 43 & $\begin{array}{l}\text { Hiatal hernia, atrophic } \\
\text { chronic gastritis }\end{array}$ & $\mathrm{N}$ & - \\
\hline 12 & 25 & M & $\begin{array}{l}\text { Celiac disease } \\
\text { and vomiting }\end{array}$ & 8.6 & 80.8 & 127 & $\mathrm{~N}$ & $\mathrm{~N}$ & Jejunal stenosis \\
\hline
\end{tabular}

DBUO: digestive bleeding of unknown origin; F: female; $\mathrm{Hb}$ : hemoglobin (reference range, 12-16 g/dl); LDB: bleeding of the lower digestive tract; M: male; MCV: mean corpuscular volume (reference range, $80-100 \mathrm{fl}$ ). The reference range for ferritin was $14-186 \mathrm{ng} / \mathrm{ml}$.

Table II. Capsule endoscopy and enteroscopy

\begin{tabular}{|c|c|c|c|c|c|}
\hline Patient number & Capsule endoscopy & Enteroscopy & $\begin{array}{l}\text { Endoscopic } \\
\text { treatment }\end{array}$ & $\begin{array}{l}\text { Marking with } \\
\text { India ink }\end{array}$ & $\begin{array}{l}\text { Marking with } \\
\text { hemoclips }\end{array}$ \\
\hline 1 & No & Jejunal stenosis with ulcers & $\begin{array}{l}\text { Dilation. } \\
\text { Injected } \\
\text { corticosteroids }\end{array}$ & - & - \\
\hline 2 & Jejunal bleeding & Jejunal angiodysplasia (3) & Argon & - & - \\
\hline 3 & Angiodysplasia & Jejunal angiodysplasia (3) & Argon & - & Yes \\
\hline 4 & Jejunal bleeding & Jejunal angiodysplasia (1) & Argon & - & Yes \\
\hline 5 & Gastric angiodysplasia & Jejunal pseudopolyps & No & - & - \\
\hline 6 & Jejunal bleeding & Jejunal angiodysplasia (4) & Argon & - & - \\
\hline 7 & Jejunal bleeding & Eroded submucosal tumor & Argon & Yes & - \\
\hline 8 & Jejunal angiodysplasia & Angiodysplasia not observed & No & - & - \\
\hline 9 & Jejunal bleeding & $\begin{array}{l}\text { Duodenal and jejunal varices, } \\
\text { hypertensive enteropathy }\end{array}$ & No & - & - \\
\hline 10 & Jejunal bleeding & Antral vascular ectasia & No & Yes & Yes \\
\hline 11 & Jejunal angiodysplasia & Angiodysplasia & Argon & - & Yes \\
\hline 12 & No & $\begin{array}{l}\text { Jejunal stenosis } \\
\text { (adenocarcinoma) }\end{array}$ & No & - & - \\
\hline
\end{tabular}

colonoscopy, and consider the role of the pediatric colonoscope when used as a push enteroscope.

In the case of jejunal lesions, we can use push enteroscopy if double-balloon enteroscopy is not available $(5,13,14)$. For many years this technique has been the most widely used and effective technique for the direct evaluation of the enteral mucosa. One of its limitations is that it can only be used to explore part of the jejunum, and, while it can reach more than $100 \mathrm{~cm}$ beyond the ligament of Treitz, a large part of the small intestine remains unexplored $(2,5)$. Nevertheless, it does enable us to provide a diagnosis in a large number of patients with undi- 

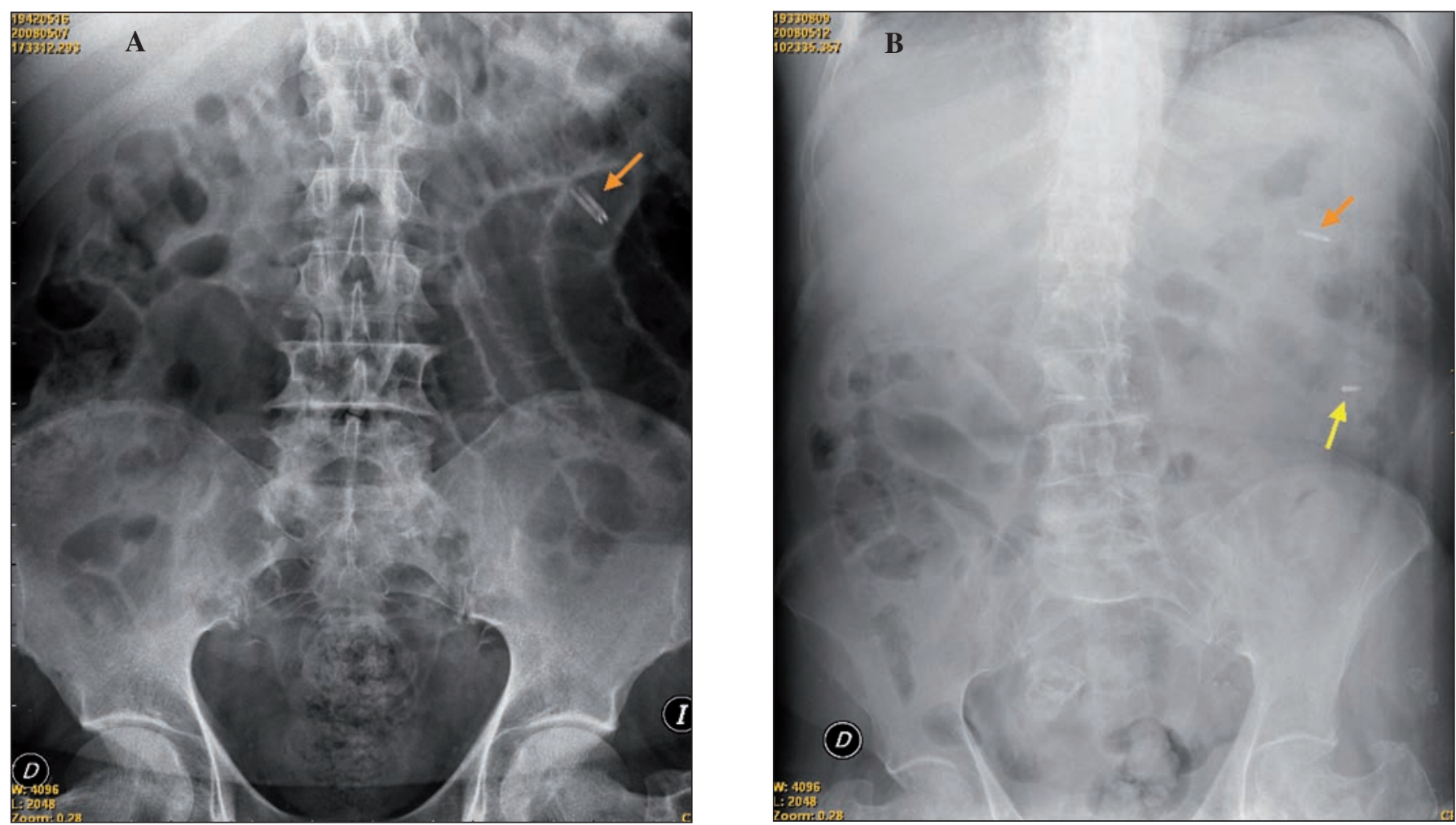

Fig. 1. Plain abdominal radiographs. A. Hemoclips on the jejunal lesion (orange arrow). B. Hemoclip on the lesion (orange arrow) and point reached using endoscopy (yellow arrow).

Radiología simple de abdomen donde se pueden ver hemoclips en la lesión yeyunal (A) y en otro paciente hemoclip en la lesión y distal al mismo donde se llegó con la endoscopia (B).

agnosed gastrointestinal bleeding, and it gives us the opportunity to treat bleeding, especially in vascular lesions. An alternative approach involves single-balloon enteroscopy $(16,17)$, which enables us to explore a greater length of the small intestine, albeit with less efficacy than with the double-balloon technique.

We must remember that capsule endoscopy is not completely reliable $(6,8,14,15)$, although it does enable us to explore the whole small intestine. Several studies have shown the superiority of this technique over other traditional approaches, including barium radiology. Nevertheless, the real significance of some findings, the false negatives due to food or liquid remains, the lack of distension or propulsion, and the excessively rapid advance through long segments $(14,15)$, are limitations that have yet to be resolved. The main disadvantage of capsule endoscopy is that it is a purely diagnostic technique with limited capacity for accurately locating the lesion and no possibility of obtaining biopsies or administering therapy $(5,8,9,15)$.

However, the most important problem we face is that not all hospitals have these diagnostic and therapeutic methods at their disposal. They are usually available in tertiary centers, although new endoscopic technology is being introduced in hospitals at other levels too. Our hospital is a secondary center and we use the diagnostic techniques available to us, such as push endoscopy, for jejunal lesions. A notable finding in our series was that 2 patients had discordant diagnoses, in which enteroscopy did not reveal the lesions expected in the section explored or there were no visible lesions. However, and perhaps more importantly, push enteroscopy by pediatric colonoscopy enabled us to treat the lesions we found (argon, dilation), take biopsy samples to establish an accurate diagnosis (stenosis due to Crohn disease, jejunal adenocarcinoma in a patient with celiac disease), and, above all, provide markings (hemoclips, India ink) to allow lesions to be located or to show the most distal point explored. The latter is an important diagnostic aid, since the lesion can be located using plain abdominal radiography or a new capsule endoscopy.

In summary, pediatric colonoscopy enables us to perform an exploration in much the same way as conventional push endoscopy (approximately $50 \mathrm{~cm}$ beyond the ligament of Treitz). It also allows us to take biopsy samples, administer treatment endoscopically, and mark lesions using standard equipment in daily practice. 


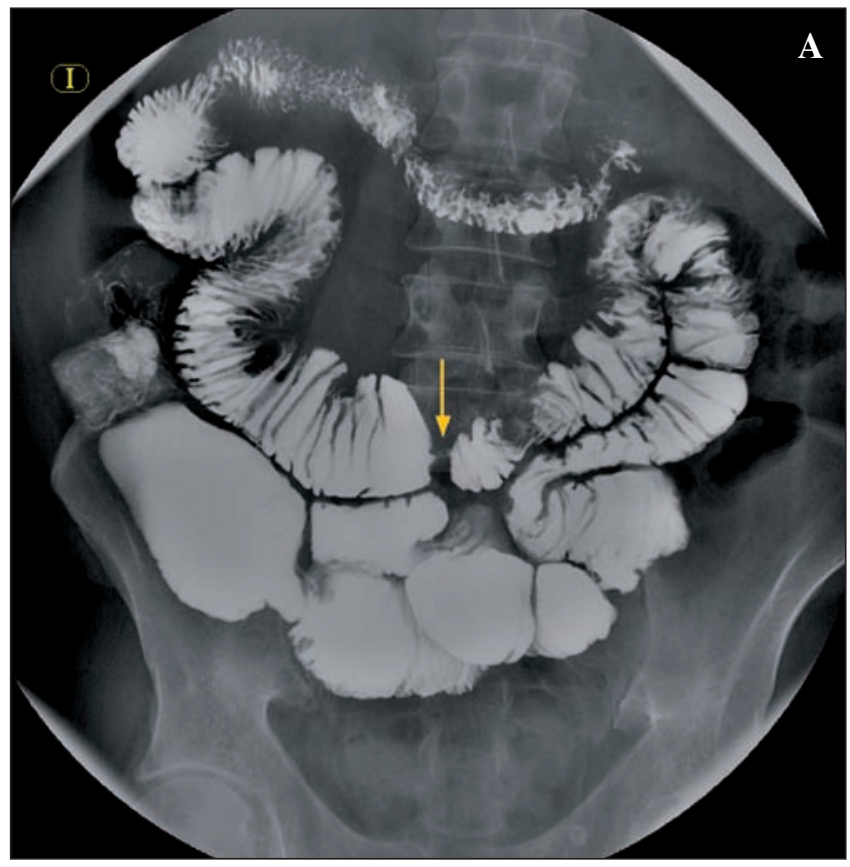

Fig. 2. Patient with jejunal stenosis due to Crohn's disease. A. Stenosis located using intestinal transit time. B. Enteroscopy reveals a 3-mm stenosis with superficial ulcers. C. A controlled radial expansion balloon is inserted to dilate the stenosis.

Paciente con estenosis yeyunal por enfermedad de Crohn que se localiza mediante tránsito intestinal (A). En la enteroscopia se ve una estenosis de $3 \mathrm{~mm}$ con úlceras superficiales (B) y que posteriormente se introduce balón CRE para dilatar (C).

\section{REFERENCES}

1. Hiratsuka H. Endoscopic diagnosis in the small intestine. Stomach Intestine 1972; 7: 1679-85.

2. Yamamoto H, Kita H. Enteroscopy. J Gastroenterol 2005; 40: 55562 .

3. Saperas E. Lower gastrointestinal bleeding: the great unknown. Gastroenterol Hepatol 2007; 30: 93-100

4. Hayat M, Axon AT, O'Mahony S. Diagnostic yield and effect on clinical outcomes of push enteroscopy in suspected small-bowel bleeding. Endoscopy 2000; 32: 369-72.

5. Gómez Rodríguez BJ, Ortiz Moyano C, Romero Castro R, Caunedo Álvarez A, Hernández Durán MD, Hergueta Delgado P, et al. Diagnostic yield of 335 push video-enteroscopies. Rev Esp Enferm Dig 2006; 98(2): 82-92.

6. Mata A, Bordás JM, Feu F, Ginés A, Pellisé M, Fernández-Esparrach G, et al. Wireless capsule endoscopy patient with obscure gastrointestinal bleeding: a comparative study with push enteroscopy. Aliment Pharmacol Ther 2004; 20: 189-94.

7. Pérez-Cuadrado E, Más P, Hallal H, Shanabo J, Muñoz E, Ortega I, et al. Double-balloon enteroscopy: a descriptive study of 50 explorations. Rev Esp Enferm Dig 2006; 98(2): 73-81.

8. Ross A, Mehdizadeh S, Tokar J, Leighton JA, Kamal A, Chen A, et al. Double balloon enteroscopy detects small bowel mass lesions missed by capsule endoscopy. Dig Dis Sci 2008; 53: 2140-3.

9. Kameda N, Higuchi K, Shiba M, Machida H, Okazaki H, Yamagami $\mathrm{H}$, et al. A prospective, single-blind trial comparing wíreless capsule endoscopy and double-balloon enteroscopy in patients with obscure
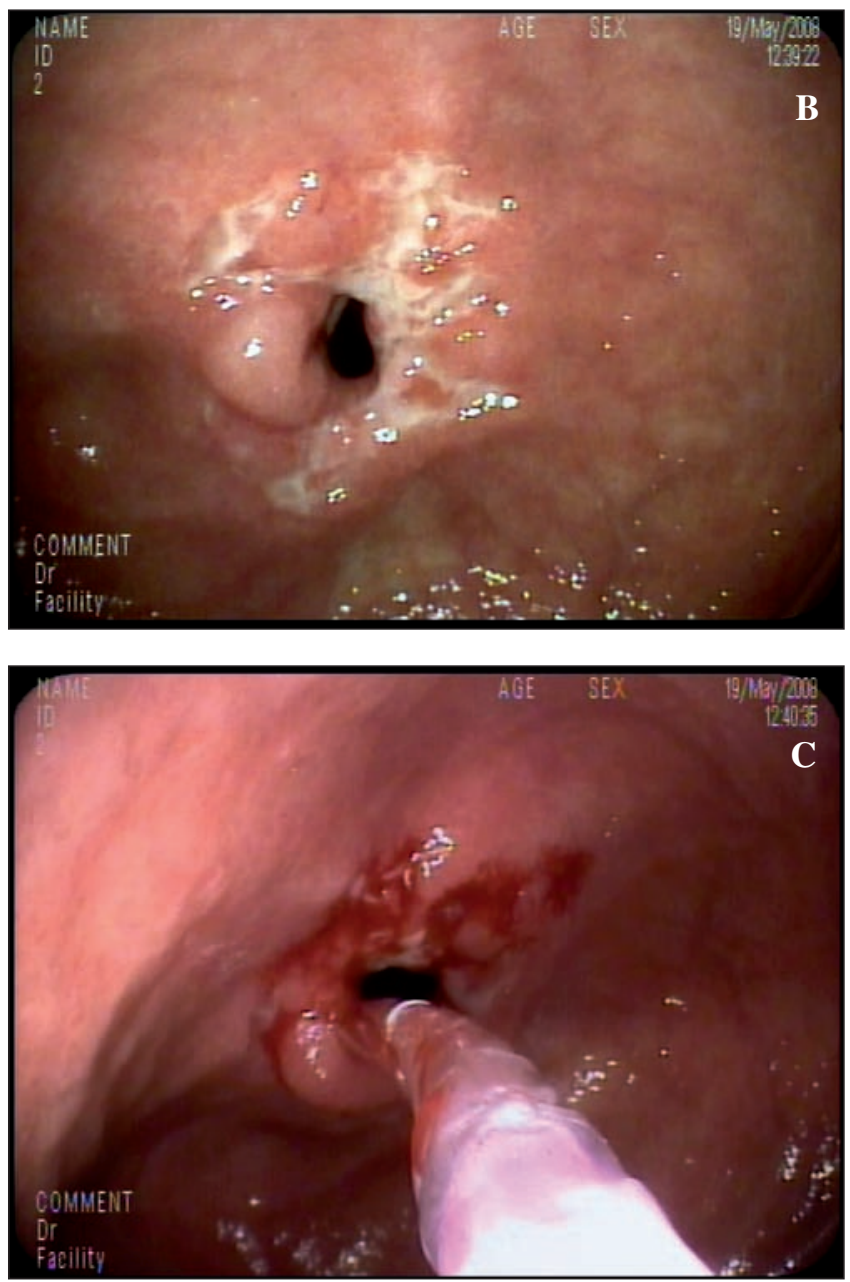

gastrointestinal bleeding J Gastroenterol 2008; 43: 434-40.

10. Mönkemüller K, Weigt J, Treiber G, Kolfenbach S, Kahl S, Röcken $\mathrm{C}$, et al. Diagnostic and therapeutic impact of double-balloon enteroscopy. Endoscopy 2006; 38: 67-72.

11. Cazzato IA, Cammarota G, Nista EC, Cesaro P, Sparano L, Bonomo $\mathrm{V}$, et al. Diagnostic and therapeutic impact of double-balloon enteroscopy (DBE) in a series of 100 patients with suspected small bowel diseases. Dig Liver Dis 2007; 39: 483-7.

12. Lo SK, Mehdizadeh S. Therapeutic uses of double-balloon enteroscopy. Gastrointest Endosc Clin N Am 2006; 16: 363-76.

13. Matsumoto T, Moriyama T, Esaki M, Nakamura S, Iida M. Performance of antegrade double-balloon enteroscopy: comparison with push enteroscopy. Gastrointest Endosc 2005; 62: 392-8.

14. Hartmann D, Schmidt H, Bolz G, Schilling D, Kinzel F, Eickhoff A, et al. A prospective two-center study comparing wireless capsule endoscopy with intraoperative enteroscopy in patients with obscure GI bleeding. Gastrointest Endosc 2005; 61: 826-32.

15. Tsujikawa T, Saitoh Y, Andoh A, Imaeda H, Hata K, Minematsu $\mathrm{H}$, et al. Novel single-balloon enteroscopy for diagnosis and treatment of small intestine: preliminary experiences. Endoscopy 2008; 40: $11-5$.

16. Kawamura T, Yasuda K, Tanaka K, Uno K, Ueda M, Sanada K, et al. Clinical evaluation of a newly developed single-balloon enteroscope. Gastrointest Endosc 2008; 68: 1112-6.

17. Postgate A, Despott E, Burling D, Gupta A, Phillips R, O'Beirne J, et al. Significant small-bowel lesions detected by alternative diagnostic modalities after negative capsule endoscopy. Gastrointestinal Endosc 2008; 68: 1209-14 